\title{
PENGARUH PERUBAHAN SUHU TERHADAP TEGANGAN TEMBUS PADA BAHAN ISOLASI CAIR
}

\author{
Alfian Junaidi \\ Jurusan Teknik Elektro, Fakultas Teknik Elektro, Universitas Tridharma \\ Jl. A. Wahab Syachranie No. 7 Batu Ampar \\ Telp. (0542) 425381 balikpapan 76126 \\ E-mail: alfianjunaidij@yahoo.co.id
}

\begin{abstract}
Lubricant oil is used to lubricate machines especially gasoline machine. To have ahighs performance lubricant oil, additive agent is added. Additive agent used for anti oxidant, anti rust of time worn, and anti foam. This research want to know the influence of temperature change on tension penetrate of lubricant oil. The sample use are lubricant oil SAE 40 and transformator oil (Diala-B). The experiment result shows that the tension penetrate of both oil are increase for increasing temperature, but lubricant oil SAE 40 have smaller increase than Diala-B.
\end{abstract}

Keywords: Iubricant oil, temperature, tension penetrate.

\section{PENDAHULUAN}

Isolator adalah alat listrik yang dipakai untuk menjalankan tugasnya mengisolasi di dalam rangkaian listrik. Alat ini mempunyai sifat atau kemampuan untuk dapat memisahkan secara elektris dua buah penghantar atau lebih yang berdekatan sehingga tidak terjadi kebocoran arus atau dalam gradien yang tinggi tidak terjadi loncatan api (flashover). Dengan demikian bahan isolasi haruslah mempunyai kekuatan dielektrik yang baik sehingga sifat hantarannya dapat ditiadakan.

Media dielektrik yang paling baik adalah ruangan vakum yang sifat hantarannya nol. Karena bahan isolator minyak bukan dielektrik sempurna, maka molekul-molekul yang terdapat pada bahan tersebut tidak terikat erat tetapi masih terdapat elektron-elektron yang dapat bergerak bebas atau dapat terlepas dari ikatan akibat menerima beban tegangan dan menimbulkan aliran arus bocor (leakage current) atau arus yang mengalir melalui media elektrik. Isolator minyak sebagian besar berasal dari minyak bumi atau minyak mentah yang diolah secara khusus sehingga mempunyai sifat-sifat sebagai isolator dan juga sebagai pendingin. Isolator minyak mineral mudah di dapat dan murah dibanding isolator minyak lain (non minyak bumi).

Isolator minyak sintetis seperti hidrokarbon sintetis, ester, hidrokarbon aromatik khlorinat, dan sebagainya, proses pembuatannya memakai reaksi kimia yang sangat mahal dan rumit juga tidak mudah di dapat unsur kimianya. Kelebihan isolator minyak sintetis adalah isolator jenis ini sederhana dalam pengoperasian peralatannya. Isolator minyak, dalam hal ini minyak transformator mempunyai unsur atau senyawa utama yaitu hidrokarbon. Senyawa hidrokarbon yang utama dari isolator minyak ini adalah senyawa hidrokarbon parafinik, senyawa hidrokarbon naftenik, dan senyawa hidrokarbon aromatik. Selain ketiga senyawa tersebut, isolator minyak masih mengandung senyawa yang disebut zat aditif (tambahan) meskipun kandungannya sangat kecil.

Minyak pelumas ini jika dibandingkan dengan minyak transformator maka minyak pelumas jenis Mesran Super SAE 40 memiliki kekentalan yang lebih tinggi dibandingkan dengan minyak trafo, hal ini sangat memberi pengaruh pada kecepatan transfer panas yang dimiliki, berdasarkan standar dari ASTM D-445 dan IEC 296A, besar kekentalan minyak atau viskositas kinematik yang dianjurkan adalah 16 eSt pada suhu 400 C. Viskositas kinematik minyak trafo $10 / 85933$ eSt. Untuk minyak trafo yang berada di pasaran viskositas kinematiknya bisa mencapai sekitar 110 eSt yakni minyak trafo produksi Shell (Diala Shell HFX).

Penelitian dilaksanakan terhadap bahan minyak lumas mesin jenis Mesran Super SAE 40 produk dari Pertamina. Tujuan penelitian ini 
adalah untuk mengetahui pengaruh suhu terhadap tegangan tembus pada bahan pengujian. Diharapkan dari hasil penelitian ini diketahui sifat yang dimaksud sehingga dengan mempertimbangkan faktor-faktor lain, bahan ini bisa merupakan alternatif untuk digunakan sebagai bahan isolasi dan pendingin untuk transformator.

\section{LANDASAN TEORI}

\section{Isolator Cair}

Isolasi cair memiliki dua fungsi yaitu sebagai pemisah antara bagian yang bertegangan dan juga sebagai pendingin sehingga banyak digunakan pada peralatan seperti transformator, pemutus tenaga, Switch gear.

\section{Minyak Trafo}

Kegunaan minyak trafo adalah selain untuk bahan isolasi juga sebagai media pendingin antara kumparan kawat atau inti besi dengan sirip pendingin. Agar minyak trafo berfungsi dengan baik, kualitas minyak harus sesuai dengan standar kebutuhan, ditunjukkan pada Tabel 1.

Tabel 1. Standar SPLN 49-1: 1982, Metoda Uji IEC 296

\begin{tabular}{|c|c|c|}
\hline Sifat Minyak & Satuan & Standar \\
\hline Viskositas $20{ }^{\circ} \mathrm{C}$ & Cst & $<25$ \\
& ${ }^{\circ} \mathrm{C}$ & $>130$ \\
\hline Titik Nyata & $\mathrm{Mg} \mathrm{KOH} / \mathrm{g}$ & $<0.40$ \\
\hline Kadar Asam & $\mathrm{KV} / \mathrm{cm}$ & $>120$ \\
\hline Teg. Tembus & - & Tidak ada \\
\hline Korosi Belerang & $\%$ & $<0.10$ \\
\hline Kotoran & \multicolumn{2}{|c}{} \\
\hline
\end{tabular}

\section{Mekanisme Ketembusan Isolasi Cair}

Ada beberapa alasan mengapa isolasi cair digunakan, antara lain yang pertama adalah isolasi cair memiliki kerapatan 1000 kali atau lebih dibandingkan dengan isolasi gas, sehingga memiliki kekuatan dielektrik yang lebih tinggi menurut hukum Paschen. Kedua isolasi cair akan mengisi celah atau ruang yang akan diisolasi dan secara serentak melalui proses konversi menghilangkan panas yang timbul akibat rugi energi. Ketiga isolasi cair cenderung dapat memperbaiki diri sendiri (self healing) jika terjadi pelepasan muatan (discharge). Namun kekurangan utama isolasi cair adalah mudah terkontaminasi.

Beberapa macam faktor yang diperkirakan mempengaruhi ketembusan minyak transformator seperti luas daerah elektroda, jarak celah (gap spacing), pendinginan, perawatan sebelum pemakaian (elektroda dan minyak), pengaruh kekuatan dielektrik dari minyak transformator yang diukur serta kondisi pengujian atau minyak transformator itu sendiri juga mempengaruhi kekuatan dielektrik minyak transformator.

Ketembusan isolasi (insulation breakdown, insulation failure) disebabkan karena beberapa hal antara lain isolasi tersebut sudah lama dipakai, berkurangnya kekuatan dielektrik dan karena isolasi tersebut dikenakan tegangan lebih. Pada prinsipnya tegangan pada isolator merupakan suatu tarikan atau tekanan (stress) yang harus dilawan oleh gaya dalam isolator itu sendiri agar supaya isolator tidak tembus. Dalam struktur molekul material isolasi, elektron-elektron terikat erat pada molekulnya, dan ikatan ini mengadakan perlawanan terhadap tekanan yang disebabkan oleh adanya tegangan. Bila ikatan ini putus pada suatu tempat maka sifat isolasi pada tempat itu hilang. Bila pada bahan isolasi tersebut diberikan tegangan akan terjadi perpindahan elektron-elektron dari suatu molekul ke molekul lainnya sehingga timbul arus konduksi atau arus bocor. Karakteristik isolator akan berubah bila material tersebut kemasukan suatu ketidakmurnian (impurity) seperti adanya arang atau kelembaban dalam isolasi yang dapat menurunkan tegangan tembus.

\section{Sifat-sifat Listrik Cair Isolasi}

Sifat-sifat listrik yang menentukan unjuk kerja cairan sebagai isolasi adalah:

a. Withstand Breakdown kemampuan untuk tidak mengalami ketembusan dalam kondisi tekanan listrik (electric stress) yang tinggi.

b. Kapasitansi listrik per unit volume yang menentukan permitivitas relatifnya. Minyak petroleum merupakan subtansi nonpolar yang efektif karena merupakan campuran cairan hidrokarbon. Minyak ini memiliki permitivitas kira-kira 2 atau 2.5. Ketidak bergantungan permitivitas subtansi nonpolar pada frekuensi membuat bahan 
ini lebih banyak dipakai dibandingkan dengan bahan yang bersifat polar. Misalnya air memiliki permitivitas 78 untuk frekuensi $50 \mathrm{~Hz}$, namun hanya memiliki permitivitas 5 untuk gelombang mikro.

c. Faktor daya: Faktor dissipasi daya dari minyak di bawah tekanan bolak balik dan tinggi akan menentukan unjuk kerjanya karena dalam kondisi berbeban terdapat sejumlah rugi rugi dielektrik. Faktor dissipasi sebagai ukuran rugi rugi daya merupakan parameter yang penting bagi kabel dan kapasitor. Minyak transformator murni memiliki factor dissipasi yang bervariasi antara $10^{-4}$ pada $20^{\circ} \mathrm{C}$ dan $10^{-3}$ pada $90^{\circ} \mathrm{C}$ pada frekuensi $50 \mathrm{~Hz}$.

d. Resistivitas: Suatu cairan dapat digolongkan sebagai isolasi cair bila resistivitasnya lebih besar dari $109 \mathrm{~W}$-m. Pada sistem tegangan tinggi resistivitasnya yang diperlukan untuk material isolasi adalah $10^{16} \mathrm{~W}$-m atau lebih $(\mathrm{W}=\mathrm{ohm})$.

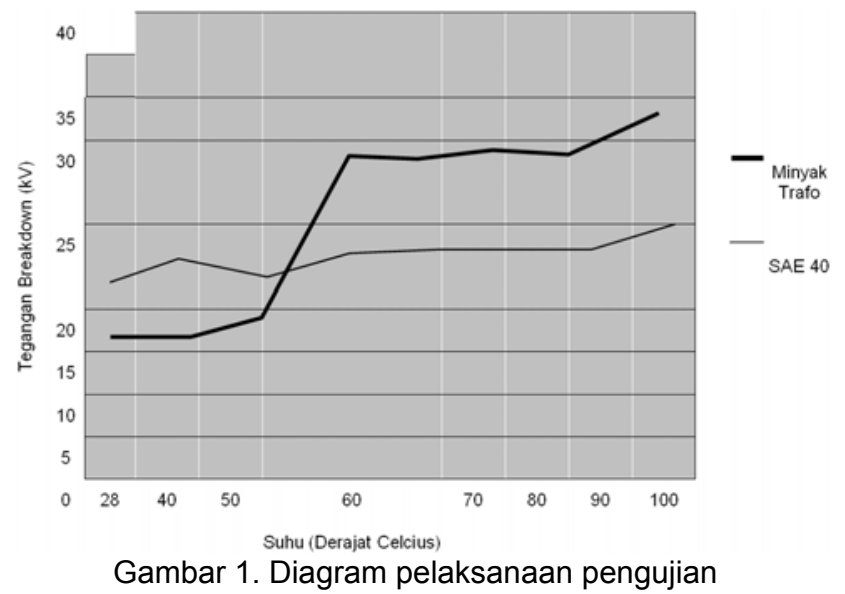

Berdasarkan standar yang dikeluarkan oleh ASTM yakni dalam standar D-877 disebutkan bahwa suatu bahan isolasi harus memiliki tegangan tembus sebesar kurang lebih $30 \mathrm{kV}$ untuk lebar sela elektroda $1 \mathrm{~mm}$, dengan kata lain kekuatan dielektrik bahan isolasi kurang lebih $30 \mathrm{kV} / \mathrm{mm}$. Sedangkan menurut standar ASTM D-1816 suatu bahan isolasi harus mampu menahan tegangan sebesar $1,2 \mathrm{~mm}$. Standar ini merupakan standar yang diterima secara internasional dan harus dipenuhi oleh suatu bahan yang dikategorikan sebagai suatu bahan isolasi.

\section{METODE PENELITIAN}

\section{Bahan Penelitian}

Penelitian ini dimaksudkan untuk mengetahui karakteristik isolasi dari suatu bahan uji yakni minyak pelumas. Jenis minyak pelumas yang digunakan sebagai bahan uji pada penelitian ini adalah jenis minyak pelumas mesin jenis Mesran Super SAE 40, produksi PT. Pertamina. Pengujian tegangan tembus bahan dilakukan dengan variasi suhu. Sehingga pada percobaan ini suhu bahan yang diuji berbeda-beda mulai dari suhu kamar hingga suhu $100^{\circ} \mathrm{C}$ dengan pengujian setiap kenaikan $10^{\circ} \mathrm{C}$. Proses pemanasan dilakukan diluar tabung penguji dengan menggunakan alat pemanas (heater). Suhu bahan selalu dipantau dengan menggunakan termometer. Sehingga apabila pada pengetesan suhu bahan turun maka dilakukan proses pemanasan kembali. Tetapi apabila suhu bahan terlalu tinggi, maka bahan ditunggu beberapa saat hingga suhunya sama dengan yang diharapkan.

\section{Peralatan Pengujian}

1. Satu set pembangkit tegangan tinggi $A C$, untuk menghasilkan tegangan tinggi $A C$ yang diperlukan untuk menguji tingkat isolasi bahan. Alat ini terdiri dari:

a. Transformator penaik tegangan.

Regulator Tegangan Primer: 100/220 Volt

Tegangan Sekunder: $\quad 50 \mathrm{kV}$

Kapasitas: $\quad 5 \mathrm{kVA}$

Berat: $\quad 125 \mathrm{Kg}$

b. Regulator, yaitu peralatan untuk mengatur besarnya tegangan keluaran transformator.

c. Voltmeter, yaitu mengukur besarnya tegangan pada sisi sekunder dan primer.

d. Resistor, digunakan untuk melindungi transformator dari arus yang besar saat terjadi tegangan tembus. Hambatan pada resistor ini bernilai 50 $\mathrm{K} \Omega$.

Peralatan di atas dibuat oleh SIEMENS Transformator Germany. 
2. Tabung penguji, untuk menguji bahan terhadap kemampuannya menahan tegangan baik AC maupun impuls. Pada tabung terdapat 2 elektroda dengan diameter 12,5 mm. Bahan terbuat dari fiber glass.

3. Barometer dan Higrometer untuk mengukur tekanan dan kelembaban udara.

4. Termometer Suhu.

5. Bahan yang akan diuji (Minyak Mesran Super SAE 40).

\section{Prosedur Penelitian}

a. Bahan uji ditempatkan pada tabung pengujian.

b. Perubahan suhu akan diberikan pada bahan yang akan di uji sesuai yang di harapkan (dirubah dari suhu kamar samapai $100^{\circ} \mathrm{C}$ dengan perubahan $10^{\circ} \mathrm{C}$ ).

c. Untuk memanaskan bahan uji pada tabung pengujian digunakan heater, dan untuk mengetahui suhu sesuai yang di kehendaki dengan termometer.

d. Pengujian Tegangan Tembus.

\section{HASIL PENELITIAN DAN PEMBAHASAN}

\section{Hasil Penelitian}

Pengukuran Tegangan Tembus minyak trafo Diala B dapat dilihat pada Tabel 2, untuk tegangan tembus minyak Mesran Super SAE 40 pada Tabel 3. Hubungan perubahan suhu masing-masing bahan dengan nilai tegangan tembus dapat dilihat pada Gambar 2.

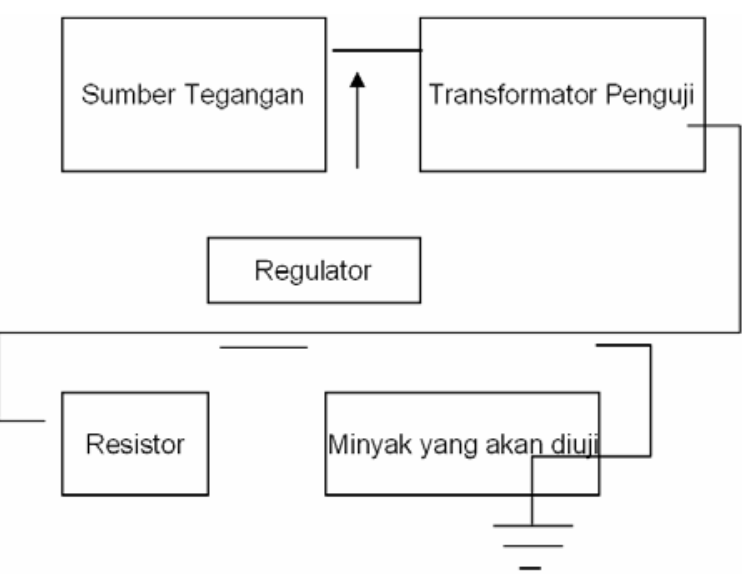

Gambar 2. Pengaruh Perubahan Suhu Terhadap Tegangan Tembus Untuk Minyak Trafo (Diala-B) dan Mesran Super SAE 40
Tabel 2. Besar Tegangan Tembus Minyak Trafo (Diala-B) Untuk suhu yang Berbeda

\begin{tabular}{|c|c|c|}
\hline No & Suhu $\left({ }^{\circ} \mathrm{C}\right)$ & $\begin{array}{c}\text { Voltage Breakdown } \\
(\mathrm{kV})\end{array}$ \\
\hline 1 & 28 & 7.825 \\
\hline 2 & 40 & 7.375 \\
\hline 3 & 50 & 10.02 \\
\hline 4 & 60 & 30.4 \\
\hline 5 & 70 & 29.625 \\
\hline 6 & 80 & 31.175 \\
\hline 7 & 90 & 30 \\
\hline 8 & 100 & 35.12 \\
\hline
\end{tabular}

Tabel 3. Besar Tegangan Tembus Minyak Pelumas Mesin SAE 40 Untuk Suhu yang Berbeda

\begin{tabular}{|c|c|c|}
\hline No & Suhu $\left.{ }^{\circ} \mathrm{C}\right)$ & $\begin{array}{c}\text { Voltage Breakdown } \\
(\mathrm{kV})\end{array}$ \\
\hline 1 & 27 & 18.417 \\
\hline 2 & 40 & 19.667 \\
\hline 3 & 50 & 18.0625 \\
\hline 4 & 60 & 20.25 \\
\hline 5 & 70 & 20.56 \\
\hline 6 & 80 & 20.5 \\
\hline 7 & 90 & 21.11 \\
\hline 8 & 100 & 23.46 \\
\hline
\end{tabular}

\section{Pembahasan}

Dari grafik data hasil percobaan, terlihat bahwa tegangan tembus tiap-tiap bahan yang diuji dalam percobaan ini mempunyai kecenderungan naik seiring dengan kenaikan temperatur. Walaupun pada level suhu tertentu beberapa bahan menunjukkan karakteristik penurunan seiring kenaikan suhu. Tetapi secara umum bisa kita dikatakan bahwa karakteristik tegangan tembus bahan-bahan yang diuji dalam percobaan adalah naik seiring dengan adanya kenaikan suhu masing-masing bahan.

Dari data pengujian diatas untuk kedua bahan tegangan akan semakin naik seiring dengan kenaikan suhu, tetapi pada bahan minyak transformator (Diala-B) cenderung lebih tinggi dibanding dengan jenis minyak Mesran Super SAE 40.

\section{KESIMPULAN}

1. Pengaruh perubahan suhu akan mempengaruhi nilai tegangan tembus (semakin meningkat suhu maka akan semakin meningkat pula nilai tegangan tembus)

2. Bahan minyak transformator (Diala-B) lebih baik mutunya (nilai tegangan tembus lebih tinggi) dibanding minyak Mesran Super SAE 40. 
Hasil penelitian menunjukkan bahwa kemampuan menahan tegangan tembus bahan isolator cair (Mesran Super SAE 40) masih di bawah standar yang ditetapkan oleh standar ASTM D-877.

\section{DAFTAR PUSTAKA}

Arigayota Abdul Rahman dan Ferry Nugraha. (1991). Minyak Berbahan Dasar Parafinik dan Naftenik, Energi dan Listrik Volume 1.

Arismunandar A. (1994). Teknik Tegangan Tinggi, Pradnya Paramita, Jakarta.

ASTM Standart. (1987). Standars Test Method for Dielectric Breakdown Voltage and
Dielectric Strenght of Solid Electrical Insulating Material at Commercial Power Frequencies, Philadelphia, USA.

Bonggas L. Tobing. (2003). Dasar Teknik Pengujian Tegangan Tinggi, Gramedia Pustaka Utama, Jakarta.

Bradwell A. (1983). Electrical Insulation, IEE Electrical and Electronic Materials and Devices Series 2, Peter Peregrinus Ltd.

Dieter Kind. (1978). Einfhrung in die Hochspannungs-Versuchtechnik. Braunschweig.

Zaky, A. A. \& R. Hawley. (1973). Conduction and Breakdown in Mineral Oil, Ltd. 